\title{
Potential of lactic acid bacteria as suppressors of wine allergies
}

\author{
Hatice Kalkan Yıldırım and Ezgi Dündar \\ Ege University, Department of Food Engineering, 35100 Bornova, Izmir, Turkey
}

\begin{abstract}
Allergens causes some symptoms as all asthma, allergic conjunctivitis, and allergic rhinitis. These symptoms are seen twice as many in women than in men. The major wine allergens reported in wines are endochitinase 4A and lipid-transfer protein (LTP). This review deal with possibilities of using lactic acid bacteria as suppressors of wine allergies. Phenolic compounds present in wines have not only antioxidant properties causing radical scavenging but also some special properties reported in many in vitro studies as regulating functions in inflammatory cells as mast cells. So what is the role of lactic acid bacteria in these cases? Lactic acid bacteria are used during malolactic fermentation step of wine production with purpose of malic acid reduction. During this bioconversion complex phenolic compounds could be hydrolysed by bacterial enzymes to their aglycone forms. Obtained aglycons could pass through the intestinal epithelium of human and allowed reduction of IgE antibody production by affecting Th1/ Th 2 ratio. Considering different contents and quantities of phenols in different grape varieties and consequently in different wines more studies are required in order to determine which lactic acid bacteria and strains could be effective in suppressing wine allergens.
\end{abstract}

\section{Introduction}

Allergy term is used to describe an inappropriate damaging immune response caused by some substance including foods. The reactions obtained could be antibody- or cellmediated. Considering clinical disease patterns, the nature of this reactions are classified as Type 1, Type 2, Type 3 and Type 4. Type 1 depends on an interaction between antigen and IgE antibody attached to mast cells. Type 2 is a cytotoxic reaction between tissue- or cell-bound antigen and $\operatorname{IgM}$ or $\operatorname{IgG}$ antibody. Type 3 is an immunecomplex reaction between circulating antigen and IgG antibody. Type 4 is a cellular immune response mediated by sensitized lymphocytes. Antigens that elicit an IgEmediated type I allergic reaction are called allergens [1].

Even the exact mechanism of activation of these antigens are not understood, the fact that antigens could penetrate mucosal tissues due to their small size and solubility allowed, T-cell activation and Th2-type response reactions. Antibody is synthesized on allergen exposure and subsequently distributed throughout the body where it promptly binds to its high affinity receptor FceR which is densely expressed on the surface of mast cells. Elevated levels reflect recent (within hours) degranulation of mast cells and can be useful where the diagnosis of anaphylaxis is uncertain [1-4].

The food represents the largest antigenic / allergic component that the human body faces during the average life span [5]. Food sensitivities are divided into two groups: primary food sensitivities and secondary ones. IgE-mediated food allergy is in the primary food sensitivity group and can cause anaphylaxis in the high level and lead to immunologic disturbances [6]. Allergens causes some symptoms as all asthma, allergic conjunctivitis, and allergic rhinitis [7]. There are many studies in which grape and wine allergy have been reported
[8-10]. Severe anaphylaxis in a patient was determined after consumption of grapes, raisins and wine, caused by lipid transfer protein (LTP) - induced IgE mediated allergy. After application of specific oral tolerance induction (SOTI) which includes allergic food at certain doses, the anaphylaxis risk was reduced [11]. In another study, in patient with IgE-mediated wine allergies was determined allergies to different foods (chicory, peach, strawberry), also [12]. The most important grape and wine allergens are endochitinases $4 \mathrm{~A}$ and $\mathrm{B}$, lipid transfer protein (LTP) and thaumatin-like proteins [13]. Pathogenassociated proteins (PR) (thaumatin, endochitinase), which are produced in response to pathogens in the grapes, are thought to protect their presence throughout the wine making process because they resist acid hydrolysis and proteases [14].

This review deal with possibilities of using lactic acid bacteria as suppressors of wine allergies.

\section{The importance of phenolic compounds}

Phenolic compounds present in wines have not only antioxidant properties causing radical scavenging but also some special properties reported in many in vitro studies as regulating functions in inflammatory cells as mast cells. Most food polyphenols are found as ester glycosides and polymers forms. Polyphenols are converted to aglycone forms by intestinal enzymes or by colonic microflora before being absorbed by the body [15]. The $\beta$-glucosidase enzyme required fo this process may be present in the food itself or may be exogenously added by intestinal enzymes or colonic microflora as mentioned above [16].

There are some studies reporting that various flavonoids have potent anti-allergic activities and treatment 
with flavonoids results in the down-regulation of serum IgE levels $[17,18]$. In a study conducted by creating wine medium with water or alcohol and water with Cabernet sauvignon wines were mixed with plasma. As a result, the non-hydrolyzed $(+)$-catechin in the plasma was undetectable, and the conjugated forms of catechins were predominant. Also reported that $\beta$-glucuronidase and arylsulfatase enzymes added to the plasma pool subsequently increased three fold the amount of extracted (+)- catechin [19]. In a study done with mice, it was suggested that after mast cells began to secrete histamine, free radicals bound to ascorbic acid in the cell and ascorbic acid protected mast cells from oxidation [20]. It has been suggested that flavonoids may protect mast cells such as ascorbic in the cell from oxidative damage [21]. In another study were investigated the effects of catechins in tea on the degranulation of mast cells. As a result, depending on reactive oxygen species (ROS) found in cell and the dose of given catechin, it possess an ability to be effective in intracellular oxidation and degranulation of mast cells [22]. In a study investigating the role of Japanese Koshu grape fermented with Lactobacillus plantarum on Type 1 allergic reactions, ovalbumin (OVA) was used to induce an allergic reaction in mice. It has been found that fermented grape marcs (at doses of $100 \mathrm{mg} / \mathrm{kg}$ fermented grape marcs / orally for 15 days) significantly reduce the $\mathrm{IgE}$ antibody response against the OVA. On the other hand, there was not found any contribution to the suppression of IgE production of non-fermented grape marcs. As a result, they indicated that grape seeds fermented with Lactobacillus plantarum had anti-allergic effects [23]. At the other state of the same study concerning, have been suggested that resveratrol originating from the red grape variety was not effective in preventing allergic reactions but Koshu white grape marcs fermented with lactic acid bacteria were effective in preventing allergic reactions [23]. Additionally, Negroamoro grape fermented with Lactobacillus plantarum was found to be effective in degranulation of mast cells in mouse mesophyll leukemia cells (RBL-2H3. This result was connected to the fact that some special phenols are released during fermentation by lactic acid bacteria $[24,25]$.

\section{Lactic acid bacteria and malolactic fermentation}

Wine production involves conversion of grape sugars to alcohol and other metabolites by yeast, and malolactic fermentation, which occurs simultaneously or sequentially with alcohol fermentation. Lactic acid bacteria convert L-malic acid to L-lactic acid by decarboxylation and affects the phenolic composition of wine, increasing the contents of total polyphenols and anthocyanins in red wine $[26,27]$. During this bioconversion complex phenolic compounds could be hydrolysed by bacterial enzymes to their aglycone forms. Obtained aglycones could pass through the intestinal epithelium of human and allowed reduction of $\operatorname{IgE}$ antibody production by affecting Th1/ Th2 ratio (Fig. 1) [23].

Many factors have an influence on phenolic contents in wines. These factors are grape variety, harvesting time, climatic conditions, soil characteristics, winemaking procedures and postproduction methods. The growth and metabolism of the lactic acid bacteria in the wine is shaped

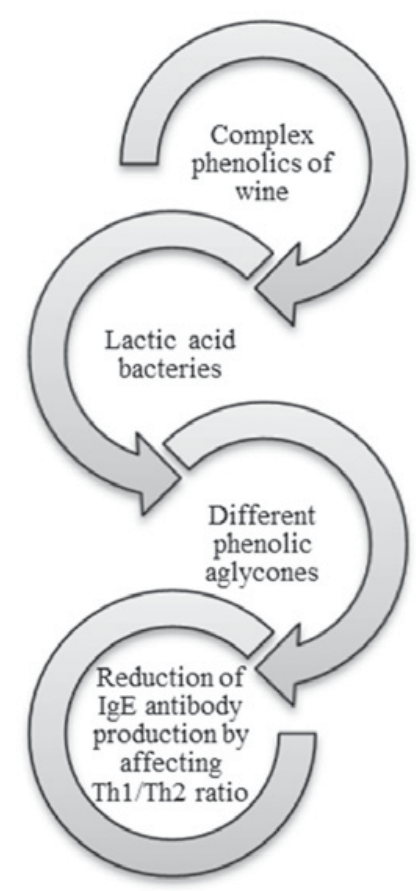

Figure 1. Effects of bioconversion of phenolic compounds with lactic acid bacteria.

by the presence of the fermentable substrate in the wine [28-30].

There are known three main genus of LAB connected with grape, grape marc and wine: Lactobacillus, Oenococcus and Pediococcus. Onenococcus oeni has been reported to be predominat species in malolactic fermentation at $\mathrm{pH}<3.5$ [31]. Lactic acid bacteria can hydrolase glycosides, reduce aldehydes to alcohols, and perform many more bioconversion in wine [26]. Many studies have reported that lactic acid bacteria convert glycosylated phenolic compounds into aglycone form through the $\beta$-glycosidase enzyme. In a study conducted by creating a synthetic wine medium with aroma components extracted from Muscat wines were used four commercial $O$. oeni strains (EQ 54, Lalvin OSU, Uvaferm Alpha, and Lalvin 31) during the malolactic fermentation and the amounts of free and bound aroma compounds were evaluated. All strains showed a decrease in glycosylated compounds at $\mathrm{pH}$ 4. However Uvaferm Alpha and Lalvin 31 strains demonstrate an ability to hydrolyze aromatic components decreased at $\mathrm{pH}$ 3.2. The results emphasized that the individual characteristics of the strains play an important role in the degree of hydrolysis of aroma compounds and therefore in changes of the chemical structure of the aglycone obtained [32]. In another study conducted by creating a synthetic wine medium of Chardonnay the effects of O.oeni Lalvin EQ54 on phenols were investigated. It has been demonstrated that glycosylated compounds were converted into the form of volatile aglycone forms (3-hydroxydamascone, alpha-terpineol, vanillin, methyl vanillate, 4-hydroxybenzoic acid and tyrosol ) by $O$. oeni's $\beta$-glycosidase enzymes. In addition, they have shown that increase the aglycone forms in the Chardonnay glycosidic extract of purely added $\alpha$-1-rhamnopyranosidase and $\alpha-1$ arabinofuranosidase enzymes. The results obtained indicate that $O$. oeni possess an enough $\beta$-glycoside enzymes to disintegrate the 
glycosides in wines [33]. In a study conducted by using of synthetic wine medium with different concentration and types of phenolic compounds was determined the effect of O. oeni CECT 4100. It has been demonstrated that Oenococcus oeni don't cause any changes in phenolic compounds after malolactic fermentation [34].

Lactic acid bacteria and their fermented products are thought to have positive effects on the immune system [35]. In a study done with Lactobacillus paracasei KW3110 were determined some positive effects as lowering the level of $\operatorname{IgE}$ and balancing effects over Th1/Th2 [36]. In a study conducted in Japan, patients with cedar pollinosis allergy were treated with citrus juice fermented by Lactobacillus plantarum YIT 0132. As a results allergic symptoms were alleviates [37].

\section{Concluding remarks}

In study many studies done at "in vitro" conditions were demonstrated the capabilities of flavonoids to regulate cellular events in inflammatory cells, such as mast cells. The main problem determined was the insufficient absorption of flavonoids and their bioavailability at "in vivo" conditions since flavonoids with the glycoside group could not pass as the intact form through the barrier of the intestinal epithelium in human adults. In case of conditions at which flavonoids are hydrolyzed by $\beta$-glucosidase to form the aglycone, the suppression of wine allergens could become possible. Owning such enzymes lactic acid bacteria have a potential to inhibit degranulation of mast cells at the reaction site. Considering different contents and quantities of phenols in different grape varieties and consequently in different wines more studies are required in order to determine which lactic acid bacteria and strains could be effective in suppressing wine allergens.

\section{References}

[1] N.F.J. Adkinson, B.S. Bochner, A.W. Burks, W.W. Busse, S.T. Holgate, R.F.J. Lemanske, R.E. O'Hehir, Middleton's allergy principles and practice, Elsevier Health Sciences (2013)

[2] D.B. Corry, F. Kheradmand, Induction and regulation of the IgE response, Nature 402 (1999)

[3] K.D. Stone, C. Prussin, D.D. Metcalfe, IgE, mast cells, basophils, and eosinophils, Allergy Clin. Immunol 125, 1-16 (2011)

[4] K.A. Packard, M.M. Khan, Effects of histamine on Th1 / Th2 cytokine balance, Int. Immunopharmacol. 3, 909-920 (2003)

[5] H.A. Sampson, Food allergy, Curr. Opin. Immunol. 2, 542-547 (1990)

[6] S.L. Taylor, S.L. Hefle, Food allergies and other food sensitivities, Food Technol. Then Chicago 55, 68-84 (2001)

[7] S.G.O. Johansson, T. Bieber, R. Dahl, P.S. Friedmann, B.Q. Lanier, R.F. Lockey, C. Motala, J.A.O. Martell, T.A.E. Platts-Mills, J. Ring, F. Thien, P.V. Cauwenberge, H.C. Williams, Revised nomenclature for allergy for global use: Report of the Nomenclature Review Committee of the World Allergy Organization, October 2003, J. Allergy Clin. Immunol. 113(5), 832-836 (2004)

[8] D.E. Clayton, W. Busse, Anaphylaxis to wine, Clin. Allergy. 10, 341-343 (1980)
[9] S.G. Schäd, J. Tracka, S. Vieths, S. Scheurer, A. Conti, E.-B. Bröcker, A. Trautmann, Wine anaphylaxis in a German patient?: IgE-mediated allergy against a lipid transfer protein of grapes, Int. Arch. Allergy Immunol 136, 159-164 (2005)

[10] M. Sbornik, J. Rakoski, M. Mempel, M. Ollert, J. Ring, IgE-mediated type-I-allergy against red wine and grapes, Allergy 62, 1339-1340 (2007)

[11] S.G. Schäd, J. Trcka, I. Lauer, S. Scheurer, A. Trautmann, Wine allergy in a wine-growing district, World Allergy Organ. J. 3, 1-5 (2010)

[12] F. Borghesan, D. Basso, F.C. Bianchi, E. Favero, M. Plebani, Allergy to wine, Allergy 59, 1135-1136 (2004).

[13] E.A. Pastorello, L. Farioli, V. Pravettoni, C. Ortolani, D. Fortunato, M.G. Giuffrida, L.P. Garoffo, A.M. Calamari, O. Brenna, A. Conti, Identification of grape and wine allergens as an endochitinase 4, a lipid-transfer protein, and a thaumatin, J. Allergy Clin. Immunol 111, 350-359 (2003)

[14] H.J.M. Linthorst, L.C. Van Loon, Pathogenesis related proteins of plants, CRC. Crit. Rev. Plant Sci. 10(2), 123-150 (1991)

[15] C. Manach, A. Scalbert, C. Morand, C. Rémésy, L. Jiménez, Polyphenols: food sources and bioavailability, Am. J. Clin. Nutr. 79, 727-47 (2004)

[16] A. Scalbert, G. Williamson, Chocolate: Modern science investigates an ancient medicine, dietary intake and bioavailability of polyphenols, J. Nutr. 130, 2073-2085 (2000)

[17] S. Yano, D. Umeda, N. Maeda, Y. Fujimura, K. Yamada, H. Tachibana, Dietary apigenin suppresses IgE and inflammatory cytokines production in C57BL/6N mice, J. Agric. Food Chem. 54, 5203-5207 (2006)

[18] S. Yano, D. Umeda, T. Yamashita, Y. Ninomiya, M. Sumida, Y. Fujimura, K. Yamada, H. Tachibana, Dietary flavones suppresses IgE and Th2 cytokines in OVA-immunized BALB/c mice, Eur. J. Nutr. 46, 257-263 (2007)

[19] J.RC. Bell, J.L. Donovan, R. Wong, A.L. Waterhouse, J.B. German, R.L. Walzem, S.E. KasimKarakas, (+) -Catechin in human plasma after ingestion of a single serving of reconstituted red wine, Am. J. Clin. Nutr. 71, 103-8 (2000)

[20] J. Ortner, The Oxidation of Endegenous Ascorbic Acid During Histamine Secretion by rat peritoneal mast cells, Exp. Cell Res. 129 (1980)

[21] E. Middleton J.R, C. Kandaswami, T.C. Theoharides, The effects of plant flavonoids on mammalian cells: implications for inflammation, heart disease, Am. Soc. Pharmacol. Exp. Ther. 52, 673-751 (2000)

[22] H. Nishikawa, S. Kitani, Tea catechins have dual effect on mast cell degranulation induced by compound 48/80, Int. Immunopharmacol. 8, 12071215 (2008)

[23] T. Tominaga, K. Kawaguchi, M. Kanesaka, H. Kawauchi, E. Jirillo, Y. Kumazawa, Suppression of type-I allergic responses by oral administration of grape marc fermented with Lactobacillus plantarum Suppression of type-I allergic responses by oral-administration of grape marc fermented with-Lactobacillus plantarum, Immunopharmacol. Immunotoxicol. 32(4), 593-599 (2010) 
[24] M. Kaneko, M. Kanesaka, M. Yoneyama, T. Tominaga, E. Jirillo, Y. Kumazawa, Inhibitory effects of fermented grape marc from Vitis vinifera Negroamaro on antigen-induced degranulation,Immunopharmacol. Immunotoxicol. 32(3), 454-461 (2010)

[25] A. Singh, S. Holvoet, A. Mercenier, Dietary polyphenols in the prevention and treatment of allergic diseases, Clin. Exp. Allergy 41, 1346-1359 (2011)

[26] A.L. Waterhouse, G.L. Sacks, D.W. Jeffery Understanding Wine Chemistry. John Wiley \& Sons (2016)

[27] M.V. Moreno-Arribas, M.C. Polo, Wine Chemistry and Biochemistry, New York: Springer (2009)

[28] G. Unden, J. Fröhlich, Biology of microorganisms on grapes, in must and in wine, $\mathrm{H}$. König (Ed), Heidelberg: Springer (2009)

[29] J.M Landete, H. Rodríguez, B. De Las Rivas, R. Muñoz, High-added-value antioxidants obtained from the degradation of wine phenolics by Lactobacillus plantarum, J. Food Prot. 70(11), 2670-2675 (2007)

[30] P. van Rensburg, I.S. Pretorius, Enzymes in winemaking: harnessing natural catalysts for efficient biotransformations - A review, South African J. Enol. Vitic. 21, special issue (2000)

[31] D. Wibowo, R. Eschenbruch, C.R. Davis, G.H. Fleet, T.H. Lee, Occurrence and growth of lactic acid bacteria in wine: A Review, Am. J. Enol. Vitic. 36, 302-313 (1985)
[32] M. Ugliano, A. Genovese, L. Moio, Hydrolysis of wine aroma precursors during malolactic fermentation with four commercial starter cultures of Oenococcus oeni, J. Agric. Food Chem. 51, 5073-5078 (2003)

[33] N.D. Incecco, E. Bartowsky, S. Kassara, A. Lante, P. Spettoli, P. Henschke, Release of glycosidically bound flavour compounds of Chardonnay by Oenococcus oeni during malolactic fermentation, Food Microbiol. 21, 257-265 (2004)

[34] C. Reguant, A. Bordons, L. Arola, N. Rozès, Influence of phenolic compounds on the physiology of Oenococcus oeni from wine, J. Appl. Microbiol. 88, 1065-1071 (2000)

[35] 1.I. Metchnikoff, The prolongation of life optimistic studies classics in longevity and aging series, Springer Publishing Company (2004)

[36] D. Fujiwara, S. Inoue, H. Wakabayashi, T. Fujii, The anti-allergic effects of lactic acid bacteria are strain dependent and mediated by effects on both Th1 / Th2 cytokine expression, Int. Arch. Allergy Immunol. 135(3), 205-215 (2004)

[37] N. Harima-Mizusawa, T. Iino, N. Onodera-masuoka, N. Kato-Nagaoka, J. Kiyoshima-Shibata, A. Gomi, H. Shibahara-Sone, M. Kano, K. Shida, M. Sakai, K. Miyazaki, F. Ishikawa, Beneficial effects of citrus juice fermented with Lactobacillus plantarum YIT 0132 on Japanese cedar pollinosis, Biosci. Microbiota, Food Heal. 33, 147-155 (2014) 